\title{
The Screening of Microorganisms Capable of Methyl Tert-Butyl Ether (MTBE) Biodegradation
}

\author{
ANDRZEJ WIECZOREK ${ }^{1 \star}$, KRYSTYNA PRZYBULEWSKA², KATARZYNA KARPOWICZ² \\ and MACIEJ J. NOWAK ${ }^{3}$ \\ ${ }^{1}$ Institute of Chemistry and Fundamentals of Environmental Protection \\ ${ }^{2}$ Department of Microbiology and Biotechnology of Environment \\ ${ }^{3}$ Department of Law and Real Estate Management \\ West Pomeranian University of Technology in Szczecin, Szczecin, Poland
}

Received 15 October 2012, revised 19 January 2013, accepted 31 January 2013

\begin{abstract}
As a result of examinations carried out, 16 strains of microorganisms able to grow on mineral media with methyl tert-butyl ether as the sole source of carbon and energy were isolated. Bacteria prevailed among the isolated microorganisms. The growth of microorganisms under laboratory conditions was long and accompanied by low biomass increase. Under the conditions of the experiment, the isolated microorganisms did not show any quantitatively measurable biodegradability of methyl tert-butyl ether (MTBE) under aerobic conditions. This requires far-reaching caution with respect to trading in MTBE-modified petrols in order to protect the natural environment in Poland against contamination with that hard-to-biodegrade substance.
\end{abstract}

Key word s: Methyl tert-butyl ether, MTBE, biodegradation of methyl tert-butyl ether, isolation of microorganisms strains, biodegradability of MTBE

\section{Introduction}

From among the huge amount of pollutants emitted to the atmosphere, volatile organic compounds (VOCs) constitute one the largest groups. They are part of crude oil, liquid fuels, various thinners and solvents, and many other products of the chemical industry. In the chemical sense, these are aliphatic, aromatic and cyclic hydrocarbons, alcohols, ketones, ethers, halogenated hydrocarbons, and other compounds. They are encountered within a broad range of concentrations in outdoor and indoor air (Massolo et al., 2010) as well as waters and soils (Lehr and Lehr, 2000).

This group of noxious volatile organic compounds includes, among others, methyl tert-butyl ether (MTBE) also called methyl tertiary-butyl ether. In the last decade of the twentieth century, its production underwent a considerable increase from 8 to 28 million tonnes (Hamid and Ali, 2004). In 2004, the MTBE production in the country of its largest consumer, i.e. in the USA, amounted to about 5.6 million tonnes (EPA, 2008). According to Grzyb and Kotowski (2001), the world consumption of MTBE in 1997 amounted to 22.6 million tonnes and its share in petrols was as follows: $1.8 \%$ in Europe and 3.4\% (ordinary formulated, unleaded petrols) and $10.8 \%$ (reformulated petrols) in the USA

In the USA, it was introduced into wide use in the 1970s, whereas in Europe it has been applied since 1985. It is being added to petrol to increase total octane number and improve combustion efficiency (Yacobucci, 2006). Besides, its application aims at reduction of carbon monoxide levels, generated during fuel combustion (EIA, 2000). Considering its high volatility, MTBE is included among volatile organic compounds.

MTBE is an easily water-soluble substance. Due to its mobility, methyl tert-butyl ether penetrates into deeper soil horizons leading additionally to the contamination of ground waters (Alimohammadi et al., 2005). MTBE may penetrate into ground water through spills and leakages from fuel storage tanks, persisting in it for a long time. Even a small leakage of 1 gallon of fuel containing $11 \%$ MTBE may lead to contamination of 4 million gallons of water with the concentration of methyl tert-butyl ether reaching up to $20 \mu \mathrm{g} / \mathrm{l}$

\footnotetext{
* Corresponding author: A. Wieczorek, Institute of Chemistry and Fundamentals of Environmental Protection, Al. Piastów 42 Street, 71-065 Szczecin, Poland; phone: + 48914494907; e-mail: anwiecz@zut.edu.pl
} 
(Davis and Thomas, 2006). Environmental problems connected with the environmental contamination by them are being discussed in original papers as well as those of the state-of-art-review type. For instance, Achten et al. (2001) describe in their original paper the situation in Germany, whereas that in the USA has been presented in a publication signed by the U.S. Environmental Protection Agency (EPA, 2008). Different aspects of introducing MTBE to petrol used in the USA, especially legal ones, are described by McGarity (2004). The scale of the arising problems is well illustrated by the following facts. In 1990 MTBE was, according to some analyses, the fastest growing chemical product in the world, nine years later adding this substance to petrol in California was forbidden, whereas in the year 2004 it was already prohibited in fifteen American states (McGarity, 2004). The largest danger for the environment from MTBE is connected with petrol leakage into the ground while filling storage tanks and from tanks improperly sealed. This has lead countries to establish certain criteria for underground storage tanks and their equipment (Barker and Marples, 2001). Moreover, requirements for the composition of gasoline, including ethers, are regulated by proper European directives, the last of which allowing 22\% content was issued in 2009 (European Parliament, 2009; Pałuchowska and Jakóbiec, 2011). Permissible content of ethers in petrol for the Polish market is determined by the regulation of the Minister of Economy from $9^{\text {th }}$ December 2008 regarding the quality requirements for liquid fuels (Minister of Economy, 2008).

Even in the first half of the 1990s of the last century, methyl tert-butyl ether continued to be considered as a non-biodegradable substance. Since then, knowledge about the susceptibility of the compound to biodegradation has been significantly expanded and it is known today that it can be broken down by certain microorganisms. This refers in particular to bacteria being active under aerobic conditions (Zhong et al., 2007) and in situations when MTBE co-occurs with simple hydrocarbons (Fortin and Deshusses, 1999a, b). A few cases of MTBE co-metabolism by fungi are also known (Hardison et al., 1997). The cases of MTBE biodegradation described in the literature were usually characterised by a slow course (Volpe et al., 2009) and small biomass yield (Deeb et al., 2000). Its biodegradation in nature is also slow - its half-life is about 2 years (Fayolle et al., 2001). Large resistance of MTBE to biodegradation is induced by the structure of its molecule, in which the ether bond and tertiary carbon atom occur simultaneously (Fayolle et al., 2001). The most characteristic intermediate products of its biodegradation are tertbutyl alcohol and formaldehyde. The biodegradation of MTBE usually starts with the attack of monooxygenase and the formation of tertiary-butoxy methanol (Fayolle et al., 2001), followed by the liberation of formaldehyde and the formation of tert-butyl alcohol. The research on MTBE biodegradation and bioremediation of MTBEcontaminated environment has been reviewed, among others, by Deeb et al. (2000); Fayolle et al. (2001) and Zanardini et al. (2002). It results from these reviews that methyl tert-butyl ether is being degraded in the aerobic environment by different microorganisms, in particular by those occurring in the environment contaminated with aliphatic hydrocarbons being found in petrols. Biodegradation under anaerobic conditions is more rarely encountered and is much slower or does not occur at all. In the opinion of Fayolle et al. (2001), the biodegradation of ethyl tert-butyl ether - being used as the replacement of MTBE by some petrol producers, including the Polish ones - should be easier. This results from the liberation after ether molecule cleavage of a molecule containing two atoms of carbon more easily undergoing hydroxylation.

Some researchers describe utilisation of the phenomenon of MTBE biodegradation in the cleaning of air contaminated with it either at the laboratory scale or in pilot applications (Fortin and Deshusses, 1999a, b; Eweis et al., 1997, 1998).

The general aim of this paper was to evaluate the vulnerability of methyl tert-butyl ether to biodegradation with the use of microorganisms harvested from sources situated within the area of the Western Pomerania under the conditions similar to those prevailing in environment. The specific aims were to isolate microorganisms from the environment and to characterise their individual abilities to biodegrade the substance with kinetic methods (so called screening). The isolated microorganisms could be used for inoculation of waters and soils in MTBE-contaminated areas in order to accelerate the processes of their self-cleaning as well as of bio-filter beds cleaning the air and water contaminated with it.

\section{Experimental}

\section{Materials and Methods}

Tested microorganisms. The first group of microorganisms used in this examination was isolated from the environment in earlier studies and is part of the collections of the Department of Microbiology and Environmental Biotechnology and the Department of Physical Chemistry and Fundamentals of Environmental Protection of the Western Pomeranian University of Technology in Szczecin. They were able to biodegrade Diesel oil (Nowak et al., 2008) and volatile organic compounds, such as styrene (Wieczorek and Przybulewska, 2008), ethylbenzene (Wieczorek and Przybulewska, 2006) and methyl isobutyl ketone (Przybulewska and 
Wieczorek, 2008). Also a broad screening was carried out to search for new microorganisms able to degrade MTBE using it as a sole source of carbon and energy.

The strains kept in these collections are as follows:

- Diesel oil-degrading bacteria labelled: b/6, b/2 and $\mathrm{b} / 7$;

- ethylbenzene-degrading bacteria: Bacillus pumilus and Rhodococcus rhodochrous;

- styrene-degrading bacteria: Agrobacterium rhizogenes and Pseudomonas aeruginosa; and

- microorganisms being able to biodegrade methyl isobutyl ketone: Gordonia terrae, Agromyces mediolanus, Rhodococcus globerulus, Gordonia bronchialis, Bacillus subtilis and Fusarium solani.

Successive microorganisms were harvested during the 1st stage of screening, i.e. screening tests, using the materials sampled from locations situated in the open ground as well as isolated locations.

Sample No. 1 - a mixture of materials:

- compost bed from styrene-degrading bio-filter (Wieczorek, 2007),

- compost bed from bio-filter installed in the "Załom" Cable Factory (Wieczorek, 2005),

- compost from municipal-industrial waste from a composting plant in Racula.

Sample No. 2 - a mixture of soil samples contaminated with oil derivatives collected from:

- "Trans-Masz" Transport and Road Construction Machinery Enterprise in Stargard Szczeciński,

- fuel depots in Kluczewo,

- "Emulex" fuel station in Stargard Szczeciński,

- liquid fuel reloading bases in military units,

- military vehicle parking lots in military barracks,

- Polish Railway and Motor Transport Enterprise grounds in fuel collection point and vehicle parking areas,

- "Lotos" fuel station in Stargard Szczeciński.

Sample No. 3 - a mixture of liquid substances coming from drains and oil separators at the fuel station in Osinowo Dolne.

Sample No. 4 - a mixture of liquid residues after the cleaning of petrol tanks from different fuel stations of the PKN "Orlen" in the Western Pomeranian Province.

Sample No. 5 - turbid water from a humidifier of the test installation being used in the Department of Physical Chemistry and Foundations of Environmental Protection of the Szczecin University of Technology, through which the MTBE-contaminated air was passed for a long time.

Sample No. 6 - a mixture of samples 1 and 2 .

Isolation of microorganisms. The isolation of microorganisms from samples 1-6 was made by direct method as well as after enrichment in liquid cultures.

Direct isolations were carried out by making two parallel lines of inoculations of the material from a series of 1:10 dilutions prepared from each sample on dishes with media according to Bushnell and Haas (1941) and Kojima etal. (1961). After incubation of cultures in $15 \mathrm{dm}^{3}$ desiccators at room temperature in an atmosphere of air saturated with MTBE vapours, single colonies being different morphologically were grafted on fresh media and again incubated under the same conditions. The MTBE saturation of the air filling desiccators was obtained by placing in them beakers with $25 \mathrm{~cm}^{3}$ MTBE.

When performing the isolations from enriching liquid cultures, the first stage, i.e. inoculations from dilutions, was omitted.

The enriching cultures, targeted by medium and substrate selection, which preceded inoculations on dishes and by definition were to facilitate the searching for most active microorganisms. They were carried out in a liquid mineral medium with MTBE as a sole source of carbon and energy according to the description of the kinetic tests presented below. Instead of inoculum, a sample of $1 \mathrm{~g}$ of environmental material was introduced. The enriching cultures established this way were differentiated from primary samples by supplementing the sample number with the letter "a".

The strains of bacteria, actinomycetes and fungi harvested by the two methods were grafted on agar slants - bacteria on a medium according to Bushnell and Haas (1941), actinomyctes on a medium according to Tsyganov et al. (1964), while fungi on a PDA medium (Honda et al. 1998).

Kinetic tests. Tests of biodegradation kinetics, treated simultaneously as confirmation tests, were carried out in a testing unit presented in Fig. 1, described in earlier papers (Wieczorek and Przybulewska, 2008, 2006). Inoculum for the inoculation of cultures carried out on a liquid medium in scrubbers of the testing set was obtained by rinsing the strains with $3 \mathrm{~cm}^{3}$ of physiological saline. For inoculation of $10 \mathrm{~cm}^{3}$ medium, $1 \mathrm{~cm}^{3}$ of inoculum was used.

The concentration of MTBE in a gas stream was determined by the chromatographic method (Wieczorek, 2005).

Based on the results of gas composition analyses and the data referring to the flow of MTBE-air mixture

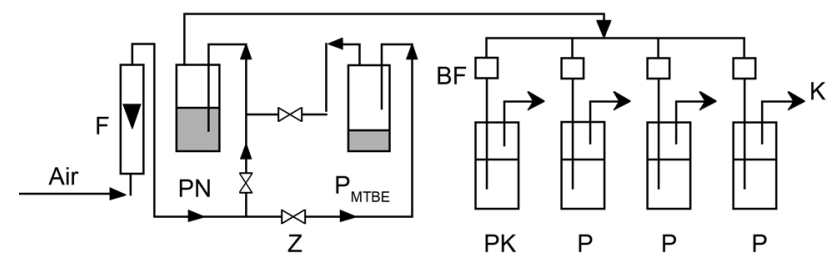

Fig. 1. Schematic of the experimental setup; F - air rotameter; PN - humidifying scrubber; BF - bacterial filters; PK - control scrubber, $\mathrm{P}$ - scrubbers with microorganisms cultures; $\mathrm{K}$ - sampling ports, $\mathrm{P}_{\mathrm{MTBE}}-$ scrubber with MTBE, $\mathrm{z}$ - valves. 
vapours, the mass loading of scrubber with MTBE was calculated, as well as total biodegradation efficiency (performance) and MTBE elimination capacity (specific biodegradation rate).

$$
\begin{aligned}
& M=\frac{G \times C_{1} \times 10^{-3}}{V} \\
& S_{u}=\frac{\left(C_{1}-C_{2}\right)}{C_{1}} \times 100 \\
& E C=\frac{G \times\left(C_{1}-C_{2}\right) \times 10^{-3}}{V}
\end{aligned}
$$

where: $\mathrm{C}_{\mathrm{i}}$ - inlet / outlet MTBE concentration, $\mathrm{mg} / \mathrm{m}^{3}$, $\mathrm{G}$ - flow rate, $\mathrm{m}^{3} / \mathrm{s}, \mathrm{V}$ - culture (suspension) volume, $\mathrm{m}^{3}$, $\mathrm{M}$ - mass loading of scrubber with MTBE, $\mathrm{g} / \mathrm{m}^{3} / \mathrm{s}$, $\mathrm{S}_{\mathrm{u}}$ - biodegradation efficiency, \%, EC - elimination capacity (biodegradation rate), g/ $\mathrm{m}^{3} / \mathrm{s}$.

\section{Results and Discussion}

Samples from the culturing of strains coming from own collections showed no ability to grow when the sole source of carbon and energy was methyl tert-butyl ether. Further tests with these microorganisms were not taken up.

As a result of the first stage of screening, i.e. screening tests, 12 bacterial strains, 3 actinomycetal strains and 1 fungal strain able to grow on mineral media in the presence of MTBE were harvested from direct samples and enriching cultures. The fact of no measurable MTBE degradation observed during carrying out the enriching cultures (Table I) requires emphasising. In
Table I the tests carried out and the obtained qualitative results are compared.

The MTBE-degrading ability by the harvested microbial strains listed in Table I was evaluated in kinetic tests, fulfilling simultaneously the role of confirmation tests.

Despite long-lasting research process, any expected activities of these microorganisms in breaking down the tested substance were clearly demonstrated qualitatively (based on the observation of culture growth) and even more evaluated quantitatively. Changes in MTBE concentrations taking place during its flow through scrubbers with liquid culture obtained in measurements were within the range of chromatographic measurement error. The description of recorded qualitative changes is presented below. After several days of enriching the cultures with MTBE-air mixture with concentrations ranging $40-500 \mathrm{mg} \cdot \mathrm{m}^{-3}$, a minimum decrease in turbidity was usually observed, followed by its small increase (initial turbidity originated from inoculum). On the other hand, no significant decrease in MTBE concentration was observed after passage through a scrubber which would be evidence of occurring biodegradation. After longer time, turbidity occurred in the humidifying scrubber (Fig. 1) where distilled water was present for the purpose of preserving proper humidity in the system, which might have been evidence of spontaneous inoculation and microbial growth. This may be explained by the fact that dusts containing waster-soluble mineral components and microorganisms penetrated into the washer due to long air purging. In the environment prepared this way, the microorganisms brought together with air found appropriate conditions

\begin{tabular}{|c|c|c|}
\hline Sample & Medium used & $\begin{array}{l}\text { Microorganisms which were isolated } \\
\text { or other information }\end{array}$ \\
\hline $\mathrm{P} 1$ & Solid mineral medium acc. to Kojima/Bushnell-Haas & No growth \\
\hline${\mathrm{P} 1 \mathrm{a}^{*}}^{*}$ & Enrichment culture, mineral medium acc. to Kojima/Bushnell-Haas & Below sensitivity level of the method \\
\hline \multirow[t]{3}{*}{$\mathrm{P} 2$} & Solid mineral medium acc. Bushnell-Haas & Actinomycete Ac1 \\
\hline & Solid mineral medium acc. Cyganov & Actinomycete Ac2 \\
\hline & MPA solid medium & Bacteria B1 \\
\hline${\mathrm{P} 2 \mathrm{a}^{*}}^{*}$ & Enrichment culture, mineral medium acc. to Bushnell-Haas & Below sensitivity level of the method \\
\hline \multirow[t]{2}{*}{ P3 } & MPA solid medium & Bacteria B2-B5 \\
\hline & Solid mineral medium acc. Bushnell-Haas & B6-B7 \\
\hline $\mathrm{P}^{2} \mathrm{a}^{*}$ & Enrichment culture, mineral medium acc. to Bushnell-Haas & Below sensitivity level of the method \\
\hline $\mathrm{P} 4$ & Solid mineral medium acc. Bushnell-Haas & Bacteria B8-B10 \\
\hline $\mathrm{P}^{2} \mathrm{a}^{*}$ & Enrichment culture, mineral medium acc. to Bushnell-Haas & Below sensitivity level of the method \\
\hline P5 & MPA solid medium & $\begin{array}{l}\text { Bacteria B11-B12 } \\
\text { Fungi F1 } \\
\text { Actinomycete Ac3 }\end{array}$ \\
\hline $\mathrm{P}^{2} \mathrm{a}^{*}$ & Enrichment culture, mineral medium acc. to Bushnell-Haas & Below sensitivity level of the method \\
\hline $\mathrm{P}^{2} \mathrm{a}^{*}$ & Enrichment culture, mineral medium acc. to Bushnell-Haas & Below sensitivity level of the method \\
\hline
\end{tabular}

Table I

Summary of the experiments 


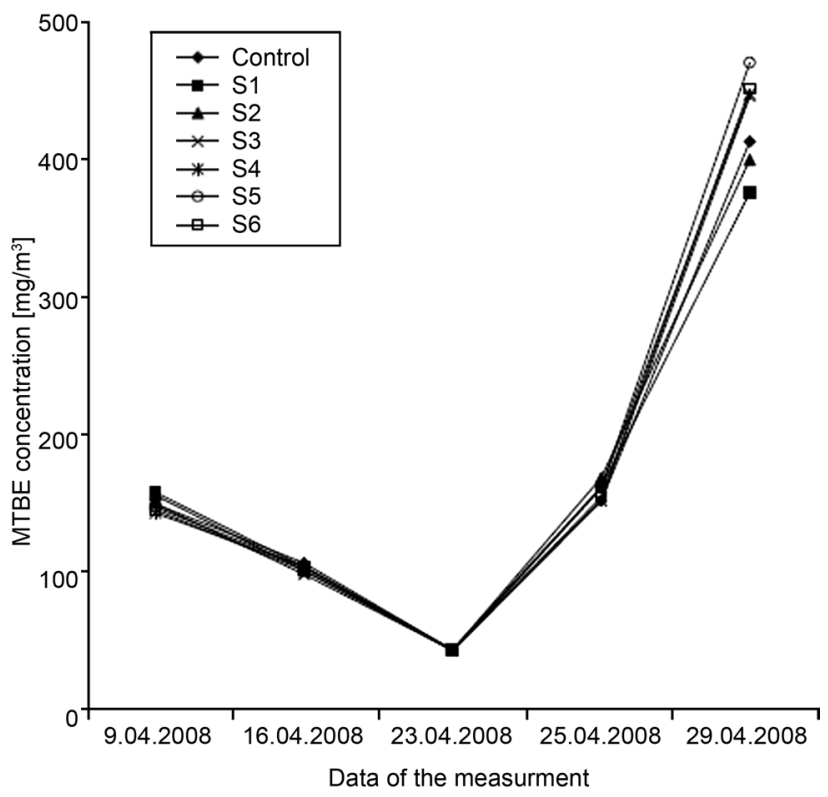

Fig. 2. Sample result from kinetic tests; S1-S6 - scrubbers with inoculated mineral medium; inoculum (sample or microorganism code): 1 - B5 + B12, 2 - B7, 3-P1, 4- B12, 5 - Ac3, 6 - Ac2

for growth. They were used as inoculum in successive measurements - sample No. 5.

Examples of quantitative results are presented in Figure 2 .

No repeatability in the sequence of point positions on successive days is evidence of the lack of a foundation for acknowledging that microorganisms present in one of the washers degraded MTBE. When assuming that the gas flow through a washer amounts to $3 \mathrm{dm}^{3} / \mathrm{h}$, the culture volume to $11 \mathrm{~cm}^{3}$, the inlet concentration to $250 \mathrm{mg} / \mathrm{m}^{3}$ and the smallest distinguishable change in concentration is equal to $10 \%$ of inlet concentration, it is possible to state that concentration drop should be at least $25 \mathrm{mg} / \mathrm{m}^{3}$ to acknowledge that biodegradation occurs. The biodegradation efficiency and its rate corresponding to it, calculated according to relationship (2) and (3), would amount respectively to $10 \%$ and $6.8 \mathrm{~g} / \mathrm{m}^{3} / \mathrm{h}$. At the lowest concentration being used, i.e. $50 \mathrm{mg} / \mathrm{m}^{3}$, measurable biodegradation rate would amount to about $1.4 \mathrm{~g} / \mathrm{m}^{3} / \mathrm{h}$. Having this in mind and assuming that MTBE biodegradation by the tested microorganisms took place, it is possible to state that its rate was smaller than $1.4 \mathrm{~g} / \mathrm{m}^{3} / \mathrm{h}$.

Summing up the measurements, it is possible to make a careful assumption that MTBE was degraded by the isolated microorganisms. This is founded on such symptoms as the occurrence of microbial growth on solid media with MTBE as a sole source of carbon and energy as well as the increase in suspension expressed by increase of liquid culture turbidity. The results of kinetic measurements indicate that the rate of that hypothetic biodegradation was very small, smaller than $1.4 \mathrm{~g} / \mathrm{m}^{3} / \mathrm{h}$.
In the reference literature, it is possible to find papers in which the authors demonstrated the occurrence of MTBE biodegradation in the natural environment or under laboratory conditions as well as its practical use (Fortin and Deshusses, 1999a, b; Charathirakup and Reungsang, 2006; Chen et al., 2006; Fortin et al., 2001; Kane et al., 2001; Lin et al., 2006, 2007; Mo et al., 1997; Schirmer et al., 2003; Schroeder etal., 2000; Zaitsev et al., 2007). From among them, Fortin and Deshusses (Fortin and Deshusses, 1999a, Fortin and Deshusses, 1999b) describe the application of biodegradation for cleaning air containing MTBE with the biofiltration method. After six-month adaptation of bio-filters, they obtained high degradation rates, approximating even $50 \mathrm{~g} / \mathrm{m}^{3} / \mathrm{h}$, with no accumulation of intermediate products and $97 \%$ conversion of substrate to $\mathrm{CO}_{2}$. Other authors describe the process of MTBE biodegradation occurring in the natural environment and / or laboratory. For instance, Kane et al. (2001), Chen et al. (2006), Charathirakup and Reungsang (2006) and Zaitsev et al. (2007) examined MTBE biodegradation with the use of microbial cultures isolated from the environment or directly from material sampled from the environment, e.g. soil, sediments, and ground water. The biodegradation rates obtained were significantly smaller than those in bio-filters. Generally, they were within the range of tenth parts to $1 \mathrm{~g} / \mathrm{m}^{3} / \mathrm{h}$. Similar biodegradation rates were obtained by Lin et al. (2007), Mo et al. (1997) and Zaitsev et al. (2007), who used pure bacterial cultures. The bacteria used by them are respectively as follows: Pseudomonas aeruginosa, Methylobacterium sp., Rhodococcus sp., Arthrobacter sp., Hyphomicrobium facilis and Methylobacterium extorquens. One of the higher rates of biodegradation with the use of pure cultures was obtained by Zaitsev et al. (2007), and its value estimated based on the research data amounting to about $1.2 \mathrm{~g} / \mathrm{m}^{3} / \mathrm{h}$. Other MTBE-mineralising strains are a broadly described PM-1, identified as Rubivivax sp. (Deeb et al., 2000), and Hydrogenophaga flava (Steffan et al., 2000). In the context of this information, it is possible to conclude that detection of the biodegradation running at smaller rates most frequently obtained in tests was not possible at the level of biodegradation detectability in scrubbers obtained in this study and assessed at $1.4 \mathrm{~g} / \mathrm{m}^{3} / \mathrm{h}$. To some extent, this explains the differences in the results obtained in this experiment, i.e. between the observed microbial growth in the presence of MTBE in plate cultures and the lack of measurable biodegradation result in kinetic measurements.

It results from reports of other authors that MTBE biodegradability strongly depends on the conditions of the process itself while a rule controlling it is hard to be detected. For instance, Volpe et al. (2009) demonstrated biodegradability of MTBE occurring independently and its lack in case of co-existence with 
aliphatic hydrocarbons. On the contrary, others found co-metabolic degradation of MTBE with light alkanes, like for example propane, pentane, etc. (e.g. Hernández et al., 2001; Haase et al., 2006; Nava et al., 2007). As a rule, these authors unanimously state biodegradation-inducing or adaptation time-reducing effect of alkanes (Hernández et al., 2001; Nava et al., 2007). However, the rate of MTBE biodegradation in the presence of alkanes is sometimes lower than when it is found alone (Kane et al., 2001).

\section{Recapitulation and Conclusions}

1. As a result of the isolation of microorganisms in the presence of a gaseous form of methyl tert-butyl ether, 16 microbial strains were harvested, with bacteria prevailing among the isolated microorganisms.

2. Microbial growth under laboratory conditions was long. It ranged from a few to several weeks, depending on the strain and the medium applied.

3. Despite broad screening, the isolated microorganisms did not show significant quantitatively determinable ability to biodegrade methyl tert-butyl ether (MTBE). This fact inspires a further search and isolation of microorganisms as well as determination of the factors deciding about their metabolic activity towards the examined compound.

4. The studies carried out point to major difficulties in isolating microorganisms from environmental samples, particularly from soil, that effectively degrade methyl tert-butyl ether under aerobic conditions and constitute indirect proof that this compound is very poorly biodegraded. This stresses the need for increasing requirements referring to trading in MTBEmodified petrols in order to ensure best possible conditions for protecting soils and waters against contamination with this substance which is little susceptible to degradation under Polish conditions.

\section{Literature}

Achten C., A. Kolb and W. Püttmann. 2001. Methyl tert-butyl ether (MTBE) in urban and rural precipitation in Germany. Atmospheric Environment 35: 6337-6345.

Alimohammadi M., Mesdaghinia A.R., Mahmoodi M., Nasseri S., A.H. Mahvi and J. Nouri. 2005. Biodegradation of MTBE by a microorganism consortium. Iran. J. Environ. Health. Sci. Eng. 2(4): 237-246.

Barker J. and A. Marples. Arthur D. Little Limited Science Park. 2001. MTBE and the Requirements for Underground Storage Tank Construction and Operation in Member States. Final Report to European Commission. ENV.D.1/ETU/2000/0089R.

Bushnell I.D. and H.E. Hass. 1941. The Utilization of Certain Hydrocarbons by Microorganisms. J. Bacteriol. 41: 653-673.

Charathirakup P. and A. Reungsang. 2006. Bioremediation treatment of MTBE and ETBE in contaminated soils. Songklanakarin J. Sci. Technol. 28(4): 853-860.
Chen K.F., Kao C.M., Chen T.Y., C.H. Weng and C.T. Tsai. 2006. Intrinsic bioremediation of MTBE contaminated groundwater at a petroleum-hydrocarbon spill site., Environ. Geol. 50: 439-445.

Davis M.J. and V.M. Thomas. 2006. Systematic Approach to Evaluating Trade-Offs among Fuel Options. Ann. N.Y. Acad. Sci. 1076: 498-515.

Deeb R.A., K.M. Scow and L. Alvarez-Cohen. 2000. Aerobic MTBE biodegradation: an examination of past studies, current challenges and future research directions. Biodegradation 11: 171-186.

EIA. 2000. MTBE, Oxygenates, and Motor Gasoline. U.S. Energy Information Administration. EIA, http://www.eia.doe.gov/emeu/ steo/pub/special/mtbe.html.

EPA. 2008. MTBE. Chapter 13. In: Regulatory Determinations Support Document for Selected Contaminants from the Second Drinking Water Contaminant Candidate List (CCL 2). EPA Report 815-R08-012, http://www.epa.gov/safewater/ccl/pdfs/reg_determine2/ report_ccl2-reg2_supportdocument_ch14_mtbe.pdf

European Parliament. 2009. Directive 2009/30/EC of the European Parliament and of the Council of 23 April 2009. Official Journal of the European Union L 140/88 5.6.2009.

Eweis J., Chang D.P., Schroeder E.D., Scow K.M., R.L. Morton and R.C. Caballero. 1997. Meeting the challenge of MTBE biodegradation. In: Proceedings of the 90th Annual Meeting and Exhibition of the Air and Waste Management Association. 8-13 June 1997. Toronto, Canada.

Eweis J., Schroeder E.D., D.P. Chang and K.M. Scow. 1998. Biodegradation of MTBE in a pilot scale biofilter, pp. 341-346. In: Wickramanayake G.B. and R.E. Hinchee (eds). Proceedings of the First International Conference on Remediation of Chlorinated and Recalcitrant Compounds. 18-21 May 1998. Monterey CA. Battelle Press, Columbus, $\mathrm{OH}$.

Fayolle F., J.P. Vandecasteele and F. Monot. 2001. Microbial degradation and fate in the environment of methyl tert-butyl ether and related fuel oxygenates. Appl. Microbiol. Biotechnol. 56: 339-349.

Fortin N.Y. and M.A. Deshusses. 1999a. Treatment of Methyl tert-Butyl Ether Vapors in Biotrickling Filters. 1. Reactor Startup, Steady-State Performance, and Culture Characteristics. Environ. Sci. Technol. 33: 2980-2986.

Fortin N.Y. and M.A. Deshusses. 1999b. Treatment of Methyl tertButyl Ether Vapors in Biotrickling Filters. 2. Analysis of the RateLimiting Step and Behavior under Transient Conditions. Environ. Sci. Technol. 33: 2987-2991.

Fortin N.Y., Morales M., Nakagawa Y., D.D. Focht and M.A. Deshusses. 2001. Methyl tert-butyl ether (MTBE) degradation by a microbial consortium. Environ. Microbiol. 3(6): 407-416. Grzyb R. and W. Kotowski. 2001. Gasoline methyl-tert-butyl ether (MTBE) in environmentally harmful (in Polish). Przem. Chem. 809(5): 182-185.

Haase K., Wendlandt K.D., A. Gräber and U. Stottmeister. 2006. Cometabolic Degradation of MTBE Using Methane-Propane- and Butane-Utilizing Enrichment Cultures and Rhodococcus sp. BU3. Eng. Life. Sci. 6(5): 508-513.

Hamid H. and M.A. Ali. 2004. Handbook of MTBE and other gasoline oxygenates. CRC Press.

Hardison L.K., Curry S.S., L.M. Ciuffetti and M.R. Hyman. 1997. Metabolism of Diethyl Ether and Cometabolism of methyl tert-butyl ether by a Filamentous Fungus, a Graphium sp. Appl. Environ. Microbiol. 63: 3059-3067.

Hernández A., Magaña M., Cárdenas B., S. Hernández and S. Revali. 2001. Methyl tert-butyl ether (MTBE) elimination by cometabolism: laboratory and biofilter pilot-scale results. In: Proceedings of Air \& Waste Management Association's $94^{\text {th }}$ Annual Meeting \& Exhibition. June 24-28. 2001. Orlando, Florida, United States. Honda N., Hirai M., T. Ano and M. Shoda. 1998. Antifungal effect of a heterotrophic nitrifier Alcaligenes faecalis. Biotechnology Letters 20(7): 703-705. 
Kane S.R., Beller H.R., Legler T.C., Koester C J., Pinkart H.C., R.U. Halden and A.M. Happel. 2001. Aerobic Biodegradation of Methyl tert-Butyl Ether by Aquifer Bacteria from Leaking Underground Storage Tank Sites. Appl. Environ. Microbiol. 67(12): 5824-5829.

Kojima Y., N. Itada and O. Hayaishi. 1961. Metapyrocatechase: a new catechol-cleaving enzyme. J. Biol. Chem. 236: 2223-2228.

Lehr J.H. and J.K. Lehr. 2000. Standard handbook of environmental science, health, and technology. McGraw-Hill Professional.

Lin C.W., S.Y. Chen and Y.W. Cheng. 2006. Effect of metals on biodegradation kinetics for methyl tert-butyl ether. Biochem. Eng. J. 32: 25-32.

Lin C.W., Y.W. Cheng and S.L. Tsai. 2007. Multi-substrate biodegradation kinetics of MTBE and BTEX mixtures by Pseudomonas aeruginosa. Process Biochemistry 42: 1211-1217.

Massolo L., Rehwagen M., Porta A., Ronco A., O. Herbarth and A. Mueller. 2010. Indoor-Outdoor Distribution and Risk Assessment of Volatile Organic Compounds in the Atmosphere of Industrial and Urban Areas. Environ. Toxicol. 25(4): 339-349.

McGarity T.O. 2004. MTBE: A Precautionary Tale. Harvard Environmental Law Review 28: 281-342.

Minister of Economy. 2008. Regulation of the Minister of Economy of 9 December 2008 on quality requirements for liquid fuels (in Polish). Dziennik Ustaw No. 221. item. 1441.

Mo K., Lora C.O., Wanken A.E., Javanmardian M., X. Yang and C.F. Kulpa. 1997. Biodegradation of methyl t-butyl ether by pure bacterial cultures. Appl. Microbiol. Biotechnol. 47: 69-72.

Nava V., M. Morales and S. Revah. 2007. Cometabolism of methyl tert-butyl ether (MTBE) with alkanes. Rev. Environ. Sci. Biotechnol. 6: 339-352.

Nowak A., Nowak J., Hawrot M., Telesiński A., Błaszak M., Kłódka D., Przybulewska K., B. Smolik and J. Szymczak. 2008. Biodegradation of diesel fuel in soil modified with compost or bentonite and optimized strains of bacteria. Part I. Residues of diesel fuel components in soil and changes in microflora activity. Ecol. Chem. Eng. A 15(6): 483-503.

Pałuchowska M. and J. Jakóbiec. 2011. Specifications of quality of motor gasoline E 10 (in Polish), Nafta-Gaz 11: 825-830.

Przybulewska K. and A. Wieczorek. 2008. Isolation and kinetic characteristic of methyl isobutyl ketone (MIBK) degrading microorganisms. Environ. Prot. Eng. 34(4): 61-67.
Schirmer M., Butler B.J., Church C.D., J.F. Barker and N. Nadarajah. 2003. Laboratory evidence of MTBE biodegradation in Borden aquifer material. J. Contam. Hydrol. 60: 229-249.

Schroeder E.D., Eweis J.B., D.P.Y. Chang and J.K. Veir. 2000. Biodegradation of Recalcitrant Components of Organic mixtures. Water, Air, and Soil Pollution 123: 133-146.

Steffan R.J., Vainberg S., Condee C., K. McClay and P. Hatzinger. 2000. Biotreatment of MTBE with a new bacterial isolate, 165-173. In: Wickramanayake G.B., Gavaskar A.R., Alleman B.C., Magar V.S. (eds) Bioremediation and phytoremediation of chlorinated and recalcitrant compounds. Battelle, Columbus, Ohio.

Volpe A., Del Moro G., Rossetti S., V. Tandoi and A. Lopez. 2009. Enhanced bioremediation of methyl tert-butyl ether (MTBE) by microbial consortia obtained from contaminated aquifer material. Chemosphere 75(2): 149-155.

Wieczorek A. 2005. Pilot-Scale biofiltration of waste gazes containing aliphatic and aromatic hydrocarbons, phenol, cresols, and other volatile organic compounds. Environ. Prog. 24: 60-66.

Wieczorek A. 2007. Biofiltration of styrene-contaminated off-gases leaving polyester laminate making plant (in Polish). Przemysl Chemiczny 86(2): 118-121.

Wieczorek A. and K. Przybulewska. 2006. Screening of microorganisms able to biodegrade ethylbenzene. Environ. Prot. Eng. 32: 47-52. Wieczorek A. and K. Przybulewska. 2008. Isolation and kinetic characteristic of styrene decomposing bacteria. Environment Protection Engineering 34(4): 91-96.

Yacobucci B.D. 2006. Alternative Fuels and Advanced Technology Vehicles: Issues in Congress. In: CRS Issue Brieffor Congress, http:// italy.usembassy.gov/pdf/other/IB10128.pdf.

Zaitsev G.M., J.S. Uotila and M.M. Häggblom. 2007. Biodegradation of methyl tert-butyl ether by cold-adapted mixed and pure bacterial cultures. Appl. Microbiol. Biotechnol. 74: 1092-1102.

Zanardini E., Pisoni C., Ranalli G., M. Zucchi and C. Sorlini. 2002. Methyl tert-butyl ether (MTBE) bioremediation studies. Ann. Microbiol. 52: 207-221.

Zhong W.H., Chen J.M., Lu Z., D.Z. Chen and X. Chen. 2007. Aerobic degradation of methyl tert-butyl ether by a Proteobacteria strain in a closed culture system. J. Environ. Sci. 19: 18-22.

Tsyganov A.A., R.A. Zhukova and K.A. Timofeeva. 1964. Morphologo-biochemical peculiarities of a new species of Actinomyces 2732/3 (in Rusian). Mikrobiologiya 33: 863-869. 
